\title{
Pengaruh Perceived Ease Of Use, Perceived Usefulness, dan Trust terhadap Intention To Use
}

\author{
Ivan Naufaldi dan Miharni Tjokrosaputro \\ Program Studi Manajemen Fakultas Ekonomi \& Bisnis, \\ Universitas Tarumanagara \\ Email: ivannauvaldi@gmail.com
}

\begin{abstract}
The purpose of this study is to examine whether perceived ease of use, perceived usefulness, and trust are positive predictors of Intention to use DANA in Jakarta. The population of this research is the DANA users who live in Jakarta, from the entire population of researchers who used only 200 people as samples selected using convinience sampling methods, by distributing questionnaires online, the data were then processed using smartPLS-SEM. The result of this research is perceived ease of use and perceived usefulness affect intention to use, and the trust can't affect the intention to use.
\end{abstract}

Keywords: Perceived Ease of Use, Perceived Usefulness, Trust, Intention to Use

Abstrak: Tujuan dari penelitian ini adalah untuk menguji apakah persepsi kemudahan penggunaan, persepsi manfaat, dan kepercayaan merupakan prediktor positif dari niat untuk menggunakan DANA di Jakarta. Populasi penelitian ini adalah pengguna DANA yang tinggal di Jakarta, dari seluruh populasi peneliti yang menggunakan hanya 200 orang sebagai sampel yang dipilih menggunakan metode convenience sampling, dengan mendistribusikan kuesioner secara online, data kemudian diproses menggunakan smartPLS-SEM. Hasil dari penelitian ini adalah persepsi kemudahan penggunaan dan persepsi kegunaan mempengaruhi niat untuk menggunakan, dan kepercayaan tidak dapat mempengaruhi niat untuk menggunakan.

Kata kunci: Persepsi kemudahaan Penggunaan, Persepsi Manfaat, Kepercayaan, Minat untuk menggunakan

\section{LATAR BELAKANG}

Sistem pembayaran dalam transaksi ekonomi mengalami kemajuan yang pesat seiring dengan perkembangan teknologi yang canggih. Di era digital yang semakin marak dengan penggunaannya $e$-wallet membuat para konsumen merasa di permudahkan dalam kegiatan jual beli. E-wallet atau dikenal juga dengan istilah dompet digital belakangan ini popularitasnya semakin menanjak. Penetrasi pembayaran lewat mobile ini pun hampir menginjak angka 30\%, berdasarkan hasil studi dari lembaga riset independen FT Confidential Research. Sehingga banyak orang yang mulai merasakan manfaat dompet digital seperti menawarkan kepraktisan, efisiensi, dan kenyaman. Di Indonesia terdapat berbagai macam jenis e-wallet yang telah ada, seperti ; Gopay, OVO, DANA, Link aja!, Jenius, i.saku, sakuku, dan DOKU. Layanan mobile payment semakin populer seiring meningkatnya pemakaian smartphone hingga 70\% dalam lima tahun terakhir di Indonesia.

\section{KAJIAN TEORI}

Teori yang digunakan dalam penelitian ini adalah Theory of Reasoned Action (TRA). Teori ini digunakan untuk memahami dan menilai seseorang bagaimana mereka dapat menerima dan menggunakan teknologi. Menurut Ajzen (2005), Theory of Reasoned Action 
(TRA) adalah sebagai salah satu teori yang menjelaskan perilaku manusia. Kemudian teori ini dikembangkan oleh Davis (1989) dan muncullah suatu konsep yang dinamai The Technology Acceptance Model (TAM). Menurut Davis (1989) The Technology Acceptance Model (TAM) adalah sebagai salah satu teori yang dianggap sebagai model paling kuat dan berpengaruh dalam perilaku penerimaan inovasi yang membahas masalah bagaimana pengguna dapat menerima dan menggunakan teknologi.

Perceived Ease of Use. Menurut Indarsin dan Ali (2017), Perceived Ease of Use adalah tingkat keyakinan seseorang bahwa menggunakan teknologi akan mengurangi upaya yang berlebihan. Menurut Cudjoe (2015), Perceived Ease of Use adalah tingkat dimana seseorang percaya bahwa menggunakan teknologi atau sistem tertentu akan bebas dari upaya. Menurut Tojib dan Tsarenko (2012), Perceived Ease of Use adalah kemudahan yang berkaitan dengan usaha dan kenyamanan pengguna teknologi tertentu. Dalam beberapa uraian diatas menurut beberapa peneliti terdahulu, Perceived Ease of Use dapat di jelaskan sebagai tingkat keyakinan suatu individu dimana mempelajari, memanfaatkan dan menggunakan teknologi dipercaya dapat memudahkan pengguna.

Pada penelitian terdahulu, Leon (2018) menyatakan bahwa Perceived Ease of Use memiliki pengaruh terhadap Intention to Use dengan nilai $p$-value $=0,008$ dan $\beta=0,113$. Peneliti Hur, Ko, dan Claussen (2012) menyatakan bahwa Perceived Ease of Use memiliki pengaruh terhadap Intention to Use dengan nilai $\mathrm{p}$-value $=0,018$. Peneliti jamshidi dan Hussin (2014) juga menyatakan bahwa Perceived Ease of Use memiliki pengaruh terhadap Intention to Use dengan nilai $t$-value 5,061 dan $\beta=0245$.

Perceived Usefulness. Menurut Alalwan (2016), Perceived Usefulness adalah seseorang percaya bahwa menggunakan teknologi atau inovasi tertentu akan meningkatkan kinerja pekerjaannya. Menurut Indarsin dan Ali (2017), Perceived Usefulness adalah kecenderungan seseorang untuk menggunakan suatu teknologi dan percaya bahwa teknologi itu akan membantunya melakukan pekerjaan yang lebih baik. Menurut Chawla dan Joshi (2019), Perceived Usefulness adalah keyakinan bahwa menggunakan suatu teknologi akan meningkatkan kinerja pengguna. Dalam beberapa uraian diatas menurut beberapa peneliti terdahulu, Perceived Usefulness dapat dijelaskan sebagai suatu persepsi atau evaluasi subjektif pengguna terhadap kemampuan yang diterima oleh teknologi tersebut.

Pada penelitian terdahulu, Chawla dan Joshi (2019) menyatakan bahwa Perceived Usefulness memiliki pengaruh terhadap Intention to Use dengan nilai $p$-value $=0,002$ dan $\beta=0,105$. Peneliti Leon (2018) menyatakan bahwa Perceived Usefulness memiliki pengaruh terhadap Intention to Use dengan nilai p-value 0,001. Peneliti Teo, Ursavas, dan Bahcekapili (2011) juga menyatakan bahwa Perceived Usefulness memiliki pengaruh terhadap Intention to Use dengan nilai t-value 3,391 .

Trust. Menurut Lu, Yang, Chau, dan Cao (2011), Trust adalah keyakinan subyektif bahwa suatu pihak akan memenuhi kewajibannya dalam situasi di mana pengawas tunduk pada ketidakpastian yang lebih tinggi dan risiko kehilangan kontrol yang lebih besar. Menurut Zhang, Lu, dan Kizildag (2018), Trust adalah keyakinan integritas, kebajikan, kompetensi dan kemampuan yang dimiliki seseorang terhadap orang lain. Menurut Zhou (2013), Trust adalah kesediaan untuk setia kepada penyedia layanan berdasarkan harapan positif terhadap perilaku penyedia layanan di masa depan.

Dalam beberapa uraian diatas menurut beberapa peneliti terdahulu, Trust dapat dijelaskan sebagai keyakinan subyektif pengguna dalam suatu hubungan yang terumana ketika adanya resiko dan ketidakpastian. 
Pada penelitian terdahulu, Chawla dan Joshi (2019) menyatakan bahwa Trust memiliki pengaruh terhadap Intention to Use dengan nilai $p$-value $=0,002$ dan $\beta=0,131$. Peneliti Ghazali, Mutum, Chong, Nguyen (2017) menyatakan bahwa Trust memiliki pengaruh terhadap Intention to Use dengan nilai p-value 0,05. Peneliti Kumar, Adlakaha, dan Muhkherjee (2018) juga menyatakan bahwa Trust memiliki pengaruh terhadap Intention to Use dengan nilai $p$-value 0,000 .

Intention to Use. Menurut Omotayo dan Adebayo (2015), Intention to Use adalah suatu kekuatan niat seseorang untuk melakukan suatu perilaku tertentu. Menurut Chemingui dan Lallouna (2013), Intention to Use adalah dimana seseorang siap untuk bertindak dan melakukan suatu perilaku yang diharapkan. Menurut Yadav dan Pathak (2017), Intention to Use adalah indikasi kesediaan individu untuk melakukan perilaku tertentu.

Dalam beberapa uraian diatas menurut beberapa peneliti terdahulu, Intention to Use dapat dijelaskan sebagai suatu kekuatan niat seseorang untuk melakukan suatu tindakan yang diinginkan.

\section{Kerangka Pemikiran}

Perceived Ease of Use (X) menjadi variabel independen, Perceived Usefulness (X) sebagai variabel independen, dan Trust juga sebagai variabel independen kemudian Intention to Use sebagai variabel dependen.

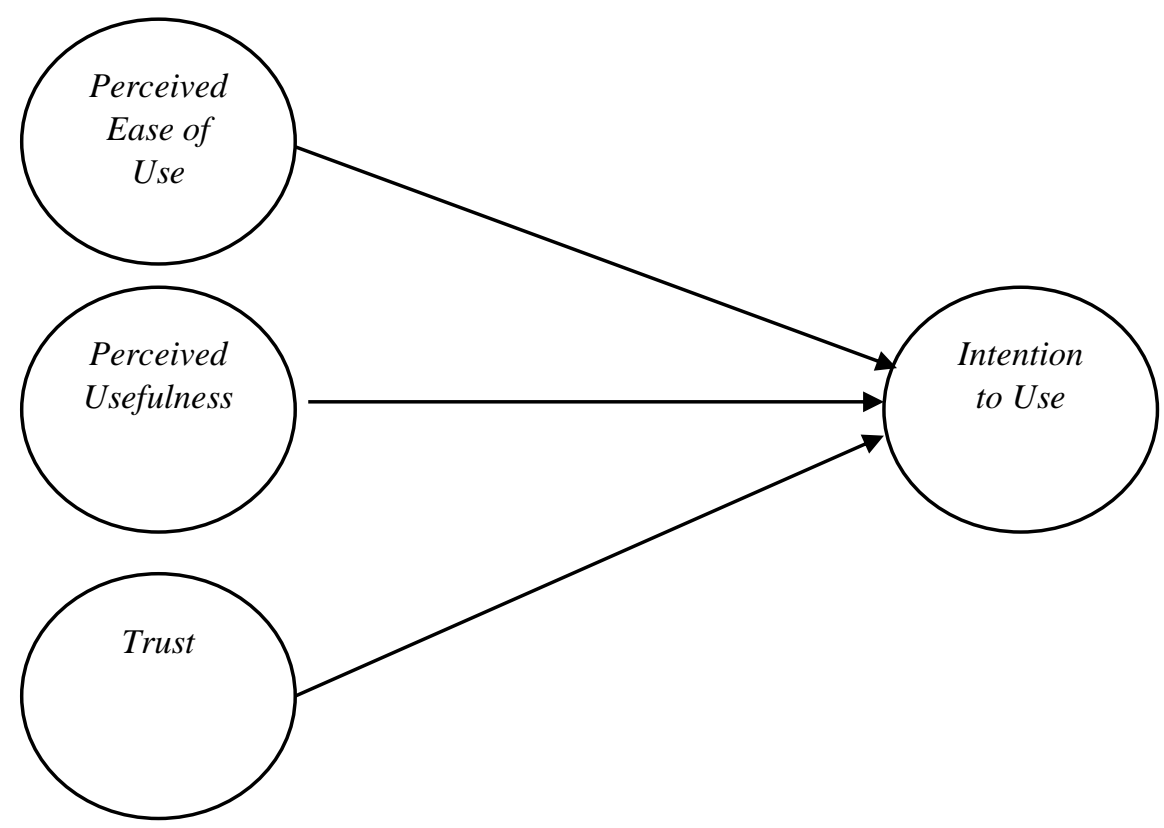

Gambar 2.1. Kerangka Pemikiran

Berdasarkan kerangka pemikiran penelitian diatas, hipotesis dari penelitian ini adalah sebagai sebagai berikut :

$\mathrm{H}_{1}$ : Perceived Ease of Use merupakan prediktor positif terhadap Intention to Use.

$\mathrm{H}_{2}$ : Perceived Usefulness merupakan prediktor positif terhadap Intention to Use

$\mathrm{H}_{3}$ : Trust merupakan prediktor positif terhadap Intention to Use. 


\section{METODOLOGI}

Subjek dan populasi dari penelitian ini adalah pengguna DANA yang berdomisili di Jakarta. Teknik pengumpulan sample yang peneliti gunakan adalah non-probability sampling dengan metode convinience sampling dengan ukuran sebanyak 200 orang. Penelitian ini menggunakan teknik analisis PLS-SEM yang terdiri dari dua analisis yaitu outer model dan inner model.

Perceived ease of Use sebagai variabel independen memiliki 3 indikator yang digunakan untuk menilai variabel dengan menggunakan skala likert, indikator tersebut terdiri dari, perasaan mudah untuk digunakan, perasaan mudah untuk dipelajari, dan perasaan tidak membutuhkan usaha lebih ketika menggunakan suatu merek tertentu, ketiga indikator tersebut peneliti adaptasi dari penelitian terdahulu (Leon,2018). Perceived Usefulness sebagai variabel independen memiliki 4 indikator yang digunakan untuk menilai variabel dengan menggunakan skala likert, indikator tersebut terdiri dari, berguna dalam kehidupan seharihari, meningkatkan produktifitas, menghemat waktu, dan membuat gaya hidup lebih mudah, keempat indikator tersebut peneliti adaptasi dari penelitian terdahulu (Leon,2018). Trust sebagai variabel independen memiliki 3 indikator yang digunakan untuk menilai variabel dengan menggunakan skala likert, indikator tersebut terdiri dari, dapat dipercaya, menepati janjinya sebagai layanan service, dan memperhatikan kepentingan pelanggan, ketiga indikator tersebut peneliti adaptasi dari penelitian terdahulu (Kumar, Adlakaha, dan Mukherjee,2017). Intention to Use sebagai variabel independen memiliki 4 indikator yang digunakan untuk menilai variabel dengan menggunakan skala likert, indikator tersebut terdiri dari, minat untuk menggunakan di masa depan, minat untuk sering menggunakan, minat untuk menggunakan dalam kehidupan sehari-hari, dan minat untuk menggunakan secara teratur, keempat indikator tersebut peneliti adaptasi dari penelitian terdahulu (Leon,2018).

\section{HASIL UJI STATISTIK}

Hasil analisis validitas menunjukkan bahwa setiap variabel telah memiliki nilai lebih dari 0.50 (Hair,2011). Maka variabel yang digunakan telah memenuhi syarat validitas konvergen berdasarkan analisis Average Variance Extracted. Serta hasil analisis composite reliability yang mengukur nilai reliabilitas dari suatu konstruk membuktikan bahwa setiap variabel penelitian memiliki nilai > 0.7 (Hair,2011). Maka indikator sudah reliabel dan dapat diandalkan.

Tabel 4.1 Hasil Analisis Validitas konvergen dan Konsistensi Internal

\begin{tabular}{|l|c|c|}
\hline \multicolumn{1}{|c|}{ Variabel } & Average Variance Extracted & Composite Reliability \\
\hline Perceived Ease of Use & 0,622 & 0,831 \\
\hline Perceived Usefulness & 0,513 & 0,808 \\
\hline Trust & 0,666 & 0,857 \\
\hline Intention to Use & 0,626 & 0,870 \\
\hline
\end{tabular}

Berdasarkan tabel 4.1, semua variabel dinyatakan valid dan reliabel dengan standar Average Variance Extracted sebesar lebih dari 0.5 dan nilai untuk Composite Reliability sebesar lebih dari 0.7 .

Kemudian untuk hasil validitas diskriminan pada penelitian ini menggunakan Heterotroit-Monotrait Ratio dengan menunjukkan bahwa seluruh nilai pada tiap indikator sudah kurang dari 0.9 (Henseler,2015) 
Tabel 4.2 Hasil Analisis Validitas Diskriminan

\begin{tabular}{|l|l|l|l|l|}
\hline $\begin{array}{l}\text { Validitas } \\
\text { Diskriminan }\end{array}$ & Intention to Use & $\begin{array}{l}\text { Perceived } \\
\text { Ease of Use }\end{array}$ & $\begin{array}{l}\text { Perceived } \\
\text { Usefulness }\end{array}$ & Trust \\
\hline $\begin{array}{l}\text { Intention to } \\
\text { Use }\end{array}$ & & & & \\
\hline $\begin{array}{l}\text { Perceived } \\
\text { Ease of Use }\end{array}$ & 0.572 & 0.837 & & \\
\hline $\begin{array}{l}\text { Perceived } \\
\text { Usefulness }\end{array}$ & 0.661 & 0.782 & 0.851 & \\
\hline Trust & 0.465 & & \\
\hline
\end{tabular}

Berdasarkan tabel 4.2 menunjukkan bahwa semua variabel memiliki nilai di bahwa 0.9 yang artinya validitas diskriminannya dikatakan valid.

Untuk reliabilitas indikatir akan dikatakan reliabel jika nilai outer loading di atas 0.4 (Hair,2011).

Tabel 4.3. Hasil Analisis Reliabilitas Indikator

\begin{tabular}{|l|l|l|l|l|}
\hline Variabel & $\begin{array}{l}\text { Perceived Ease of } \\
\text { Use }\end{array}$ & $\begin{array}{l}\text { Perceived } \\
\text { Usefulness }\end{array}$ & Trust & $\begin{array}{l}\text { Intention to } \\
\text { Use }\end{array}$ \\
\hline PEOU 1 & 0.786 & & & \\
\hline PEOU 2 & 0.785 & & & \\
\hline PEOU 3 & 0.785 & & & \\
\hline PU 1 & & 0.765 & & \\
\hline PU 2 & & 0.741 & & \\
\hline PU 3 & & 0.675 & & \\
\hline PU 4 & & 0.681 & & \\
\hline TR 1 & & & 0.846 & \\
\hline TR 2 & & & 0.828 & \\
\hline TR 4 & & & 0.773 & \\
\hline ITU 1 & & & & 0,781 \\
\hline ITU 2 & & & & 0,797 \\
\hline ITU 3 & & & & 0.848 \\
\hline ITU 4 & & & & 0,734 \\
\hline
\end{tabular}

Berdasarkan tabel 4.3 maka untuk setiap indikator sudah dinyatakan reliabel karena memiliki nilai diatas 0.4 .

Kemudian hasil multikolinearitas (Table 4.4) yang menguji apakah terdapat korelasi antar variabel di dalam model regresi pada penelitian ini dapat dikatakan baik karena memiliki nilai VIF kurang dari $10(<10)$. Maka tidak terdapat multikolinieritas antar variabel bebas. Selanjutnya hasil analisis $R$-square (Tabel 4.5) menunjukkan pengaruh mendekati nilai 1 yang mewakili akurasi prediktif paling lengkap. Kemudian nilai koefisien determinan pada penelitian ini memiliki tingkatan lemah karena memiliki nilai diantara 0.25 dan 0.50 . kemudian untuk $\mathrm{f}$ square kriteria nilai dimulai dari $<0.02=$ tidak berarti, $0.02=$ lemah, $0.15=$ moderat, dan $0.35=$ kuat. 
Tabel 4.4 Hasil Uji Multikolinearitas

\begin{tabular}{|l|c|c|}
\hline Variabel & Intention to Use & Keterangan \\
\hline Perceived Ease of Use & 1,667 & Tidak ada multikolinearitas \\
\hline Perceived Usefulness & 1,783 & Tidak ada multikolinearitas \\
\hline Trust & 1,795 & Tidak ada multikolinearitas \\
\hline
\end{tabular}

Berikut adalah hasil uji analisis dari R Square :

Tabel 4.5. Hasil Analisis R Square

\begin{tabular}{|l|c|}
\hline Variabel & R Square \\
\hline Intention to Use & 0.308 \\
\hline
\end{tabular}

Berdasarkan tabel 4.5 menunjukkan bahwa besarnya nilai koefisien determinasi Intention to Use adalah sebesar 0.308 (lemah).

Selanjutnya adalah hasil analisis dari $f$ Square dapat dilihat sebagai berikut :

Tabel 4.6. Hasil Analisis $f$ Square

\begin{tabular}{|l|c|}
\hline \multicolumn{1}{|c|}{ Variabel } & Intention to Use \\
\hline Perceived Ease of Use & 0,039 \\
\hline Perceived Usefulness & 0,125 \\
\hline Trust & 0,000 \\
\hline
\end{tabular}

Berdasarkan tabel 4.6 menunjukkan bahwa variabel independen Perceived Ease of Use dan Perceived Usefulness memiliki efek yang lemah terhadap variabel Intention to Use dan untuk variabel Trust tidak memiliki efek terhadap variabel Intention to Use.

Kemudian hasil analisis Path Coefficient dan signifikansi sebagai berikut :

Tabel 4.7. Hasil Analisis Path Coefficient dan Signifikansi

\begin{tabular}{|l|c|c|}
\hline \multicolumn{1}{|c|}{ Variabel } & P-value & $\boldsymbol{\beta}$ \\
\hline Perceived Ease of Use $\rightarrow$ Intention to Use & 0.006 & 0,213 \\
\hline Perceived Usefulness $\rightarrow$ Intention to Use & 0.000 & 0,393 \\
\hline Trust $\rightarrow$ Intention to Use & $\mathbf{0 , 8 8 4}$ & $\mathbf{0 , 0 1 5}$ \\
\hline
\end{tabular}

Berdasarkan tabel 4.7, Perceived Ease of Use memiliki nilai p-value 0.006 (signifikan) dan nilai $\beta$ sebesar 0.213 (positif), artinya Perceived Ease of Use merupakan prediktor positif untuk Intention to Use. Selanjutnya Perceived Usefulness memiliki nilai p-value 0.000 (signifikan) dan nilai $\beta$ sebesar 0.393 (positif), artinya Perceived Usefulness merupakan prediktor positif untuk Intention to Use. Kemudian Trust memiliki nilai p-value 0.884 (tidak signifikan) dan nilai $\beta$ sebesar 0.015 (positif), artinya Trust merupakan prediktor positif namun tidak signifikan untuk Intention to Use. 


\section{DISKUSI} berikut :

Berdasarkan hasil analisis Path Coefficient dan signifikansi dapat disimpulkan sebagai

Tabel 5.1. Kesimpulan Hasil

\begin{tabular}{|c|l|c|}
\hline HIPOTESIS & \multicolumn{1}{|c|}{ PERNYATAAN HIPOTESIS } & HASIL \\
\hline $\mathrm{H}_{1}$ & Perceived Ease of Use $\rightarrow$ Intention to Use & Didukung \\
\hline $\mathrm{H}_{2}$ & Perceived Usefulness $\rightarrow$ Intention to Use & Didukung \\
\hline $\mathrm{H}_{3}$ & Trust $\rightarrow$ Intention to Use & Tidak Didukung \\
\hline
\end{tabular}

Berdasarkan hasil pemaparan tabel 5.1, hipotesis satu dan 2 didukung, hanya hipotesis tiga yang tidak didukung karena memiliki nilai signifikansi yang tidak memenuhi syarat yakni harus dibawah 0.05 .

\section{KESIMPULAN}

Berdasarkan hasil riset maka dapat disimpulkan bahwa adalah Perceived Ease of Use dapat mempengaruhi Intention to Use, Perceived Usefulness dapat mempengaruhi Intention to Use dan Trust tidak dapat mempengaruhi Intention to Use. Berdasarkan penelitian yang telah dilakukan, peneliti akan memberikan berapa saran yang diharapkan dapat berguna bagi perusahaan DANA dan bermanfaat pula bagi penelitian sejenis yang akan dilakukan di masa mendatang. Disarankan agar DANA tetap mempertahankan dan meningkatkan kemudahan penggunaan yang sudah dimiliki. Kemudiaan disarankan agar perusahaan untuk tetap mempertahankan dan meningkatkan manfaat yang dirasakan karena pengaruh dari segi ini sangat dominan dalam meningkatkan minat menggunakan DANA, yang bertujuan agar para konsumen tidak berpindah ke $e$-wallet yang lain. Maka peneliti menyarankan DANA untuk tetap mempertahankan dan memberikan kepercayaan kepada konsumen dengan cara memberikan promo-promo atau cashback kepada konsumen agar dapat mempengaruhi minat konsumen untuk menggunakan DANA. Untuk penelitian selanjutnya, disarankan menggunakan variabel lainnya seperti Lifestyle Compability, Security, dan Attitude, sehingga penelitian ini bisa berkembang dan memiliki manfaat yang lebih, kemudian penambahan jumlah sampel, perkembangan wilayah, dan perluasan karakteristik repsonden juga diperlukan agar hasil data yang didapatkan menyerupai kondisi asli dilapangan serta manfaat yang diperoleh bisa digunakan oleh masyarakat luas.

\section{DAFTAR PUSTAKA}

Ajzen, Icek., (2005). Attitudes, Personality, and Behavior. 2nd Edition. New York : Open.

Alalwan, A. A., Dwivedi, Y. K., Rana, N. P., \& Simintiras, A. C. (2016). Jordanian consumers' adoption of telebanking: Influence of perceived usefulness, trust and self efficacy. International Journal of Bank Marketing, 34(5), 690-709.

Chawla, D., \& Joshi, H. (2019). Consumer attitude and intention to adopt mobile wallet in India-An empirical study. International Journal of Bank Marketing, 37(7), 15901618.

Chemingui, H., \& Ben lallouna, H. (2013). Resistance, motivations, trust and intention to use mobile financial services. International Journal of Bank Marketing, 31(7), 574-592. 
Cudjoe, A. G., Anim, P. A., \& Nyanyofio, J. G. N. T. (2015). Determinants of mobile banking adoption in the Ghanaian banking industry: a case of access bank Ghana limited. Journal of Computer and Communications, 3(02), 1.

Davis, F. D. (1989). Perceived usefulness, perceived ease of use, and user acceptance of information technology. MIS quarterly, 319-340.

Ghazali, E. M., Mutum, D. S., Chong, J. H., \& Nguyen, B. (2018). Do consumers want mobile commerce? A closer look at M-shopping and technology adoption in Malaysia. Asia Pacific Journal of Marketing and Logistics, 30(4), 1064-1086.

Hair, J. F., Ringle, C. M., \& Sarstedt, M. (2011). PLS-SEM: Indeed a silver bullet. Journal of Marketing theory and Practice, 19(2), 139-152.

Henseler, J., Ringle, C. M., \& Sarstedt, M. (2015). A new criterion for assessing discriminan validity in variance-based structural equation modeling. Journal of the academy of marketing science, 43(1), 115-135.

Hur, Y., Ko, Y. J., \& Claussen, C. L. (2012). Determinants of using sports web portals: An empirical examination of the sport website acceptance model. International Journal of Sports Marketing and Sponsorship, 13(3), 6-25.

Indarsin, T., \& Ali, H. (2017). Attitude toward Using m-Commerce: The Analysis of Perceived Usefulness Perceived Ease of Use, and Perceived Trust: Case Study in Ikens Wholesale Trade, Jakarta-Indonesia. Saudi Journal of Business and Management Studies, 2, 995-1007.

Jamshidi, D., \& Hussin, N. (2016). Forecasting patronage factors of Islamic credit card as a new e-commerce banking service: an integration of TAM with perceived religiosity and trust. Journal of Islamic Marketing, 7(4), 378-404.

Kumar, A., Adlakaha, A., \& Mukherjee, K. (2018). The effect of perceived security and grievance redressal on continuance intention to use M-wallets in a developing country. International Journal of Bank Marketing, 36(7), 1170-1189.

Leon, S. (2018). Service mobile apps: a millennial generation perspective. Industrial Management \& Data Systems, 118(9), 1837-1860.

Lu, Y., Yang, S., Chau, P. Y., \& Cao, Y. (2011). Dynamics between the trust transfer process and intention to use mobile payment services: A cross-environment perspective. Information \& Management, 48(8), 393-403.

Teo, T., Faruk Ursavaş, Ö., \& Bahçekapili, E. (2011). Efficiency of the technology acceptance model to explain pre-service teachers' intention to use technology: A Turkish study. Campus-Wide Information Systems, 28(2), 93-101.

Tojib, D., \& Tsarenko, Y. (2012). Post-adoption modeling of advanced mobile service use. Journal of Business Research, 65(7), 922-928.

Yadav, R., \& Pathak, G. S. (2017). Determinants of consumers' green purchase behavior in a developing nation: Applying and extending the theory of planned behavior. Ecological Economics, 134, 114-122.

Zhang, T., Lu, C., \& Kizildag, M. (2018). Banking “on-the-go": examining consumers' adoption of mobile banking services. International Journal of Quality and Service Sciences, 10(3), 279-295.

Zhou, T. (2013). An empirical examination of continuance intention of mobile payment services. Decision support systems, 54(2), 1085-1091 